\title{
JIC: Scientific Initiation Day to Promote University Research From Early Stages
}

\author{
Alexis Tejedor De León \\ Universidad Tecnológica de Panamá
}

\begin{abstract}
To build "research culture" from early phases in student training, the Universidad Tecnologica de Panama implemented the Scientific Initiation Day (JIC). This problem-based learning model consists of presenting research projects as complementary activities to those developed in classrooms, within the scope of a particular subject. At the beginning of the academic period, questions - problems are formulated - and through the use of the scientific method, the teams, of up to 4 students, try to find a solution to the problem posed; being that the key to success lies in the professor, who serves as a research advisor. At the end, the projects are presented to a panel of external judges and are evaluated according to the written scientific article, the oral presentation and the poster delivered. The best evaluated projects participate in the National JIC that includes all the accredited universities in Panama, who have also adopted this educational model.
\end{abstract}

Keywords: problem-based learning, university research, research culture

\section{EXPERIENCE BACKGROUND}

The Programa Institucional de Iniciación Científica - PIIC (Institutional Program of Scientific Initiation) of which the Scientific Initiation Day is a cornerstone, is based on the principle that "the university is not a degree mill", but understands that the university ecosystem is focused on science, technology and innovation, necessary to fully promote the training of human resources within it, whether they are teachers, researchers, administrative and/or undergraduate and graduate students. In other words, universities are real spaces for strengthening the tripod: research, knowledge production, and full and critical citizen training, which are achieved through the implementation of different programs and projects.

The background of the Jornada de Iniciación Científica - JIC (Scientific Initiation Day) goes back to an educational project called IsCLA (Research in the Classroom) of which the Salón de Iniciación Científica - SIC (Scientific Initiation Hall) and the Muestra de Trabajos y Proyectos Técnicos - MTPT (Exhibition of Technical Works and Projects) were the precursors and were launched in 2002 at the Faculty of Mechanics of the Veraguas Regional Center of the Technological University of Panama: Since 2015, the "JIC" has been underpinned as a university environment where undergraduate and technology students can present projects completed during the semester either in the form of exhibits, written work or in oral presentations. This idea arose in response to the lack of research promotion activities at the institutional level, but more than this, its importance lies in the type of projects that have been presented and the way in which they are disclosed or evaluated. 


\section{JUSTIFICATION AND RELEVANCE}

The Technological University of Panama (UTP) in its program called PIIC aims to develop scientific thinking at early levels of university education and introduce students to the research and innovation practice by fostering attitudes towards science, giving them the opportunity to connect with scientific methodology, making a difference in the prospects of university youth towards global competitiveness through the skills to face and solve real life problems common in local, regional and global society. The PIIC is based on meeting the objectives for solving the problems of Panamanian society and the region, which is constantly seeking to improve the life quality conditions, with full respect and harmony with the environment and social equity. In this sense, the JIC is focused on increasing productivity and competitiveness through technology transfer and support for innovation and entrepreneurship, on the one hand, and the generation of new knowledge, on the other.

The important figure in this event is the teacher advisor, who must shape his/her subject to include a project that meets the standards of innovation and scientific methodology required in the JIC and at the same time with the subject curriculum encouraging critical thinking, observation to promote innovation, entrepreneurship and research in the student. Many of the teachers must introduce scientific methodology as part of the subject matter, while advising students on writing scientific papers, preparing posters and coaching oral presentations. Outside of the classroom, time is required for providing feedback on projects and articles developed by students. Since this is a scientific induction, many of these projects will not be developed as scientific projects and some are not even at a level to be published in the "Revista de Iniciación Científica" (Journal of Scientific Initiation), leaving the teacher advisor with the satisfaction of having initiated a student into the scientific world.

\section{OBJECTIVES}

- To build a scientific policy for the Technological University of Panama throughout the national territory;

- To promote an adequate diffusion of the knowledge and actions carried out at the Technological University of Panama; to incorporate extension and research activities into the life of the university community.

\section{Specific Objectives}

- To awake the scientific vocation;

- to encourage potential new talents among undergraduate students;

- to stimulate the development of scientific thinking and creativity.

\section{CONCEPTUAL BASIS}

Nowadays, the culture of the information society, based on the principle of cultural and economic globalization, constitutes a mandatory reference in the new information society, so that the new didactic models of teaching seek, among other things, to prepare versatile, restless students, who have the ability to acquire knowledge by different means, to select relevant information and to determine what they consider convenient to address real complex problems (GALLEGO BADILLO, 2004). But more than that, that they are able to learn how to learn throughout life 'Lifelong learning - LLL-' (BOUD \& FALCHIKOV, 2006), obtaining information and using it to produce knowledge. That is the reason why the emerging didactic models, within constructivist pedagogies, should prepare students to think for themselves and, in this case, more than all the knowledge learnt, what is required is the ability to analyze, interpret, synthesize and act in any situation to be solved, among the multiple and unprecedented problems in a future profession (AYAS, 2006). However, these approaches are not new; since the late 1960s, a teaching model had already been proposed that dispensed with lectures and developed the creative capacity of students through 
questions and open-ended problems (HYTTE, 2007). The "APBr" Learning based on problems or projects or learning based on the formulation of a problem and organized on the basis of a project is the learning that is produced as a result of the effort made by the individual to solve a problem (KOLMOS, 2004; HMELO-SILVER, 2004) or to carry out a given project. In the ABPr methodology, teachers or academic tutors propose one or several projects, usually inspired by real problems, at the beginning of the academic periods, which students must solve in small groups (DOCHY et al, 2006). Figure 1 shows the roles of the stakeholders and the main expected results of the ABPr.

\section{FIGURE 1}

\section{SCHEMATIZATION OF THE STAKEHOLDERS' ROLES IN THE JIC METHODOLOGY}

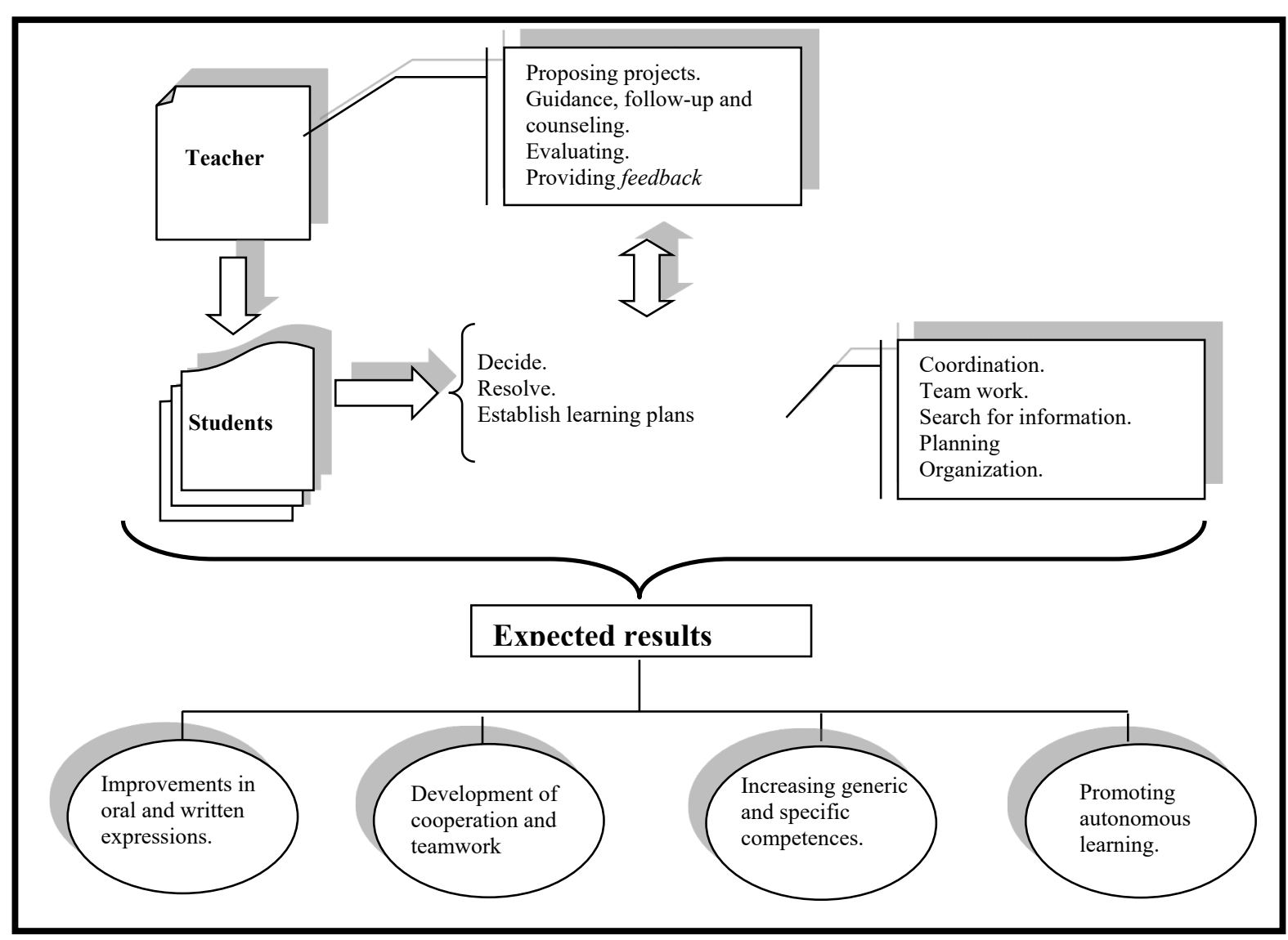

However, the ABPr also offers some drawbacks or difficulties that should be taken into account when it comes to improving and renewing the practical action of teaching. For example, there is a deeper understanding of some knowledge (especially those involved in the projects), but eventually when many other knowledge is approached in a more superficial way (or not dealt with at all), it is not always well accepted by the teaching staff. On the other hand, the aforementioned change in the teacher's role is not trivial, and requires a technique and a corresponding learning period.

\section{EXPERIENCE DESCRIPTION}

As a tutor of this active pedagogical strategy, during these fifteen years, the concept of classroom research has been used (TEJEDOR, 2016). This concept is basically based on three types of learning: project-based learning, collaborative learning and applied learning, which is consolidated in the university didactics of research-based learning considering in its development, the scientific method, under the 
principle of conceiving, designing, implementing and operationalizing (CDIO) a problem situation (TEJEDOR, 2017).

For this reason, the elaboration of scientific articles and posters, in addition to the oral presentations of each paper and suitable dissemination tools, constitute the evaluation criteria of the problem-based projects. Through classroom research, students become familiar with the procedures and methods necessary for the presentation of scientific papers at congresses and workshops, thus awakening curiosity towards research and extension. The figure below describes the methodology used in the implementation of the ABPr, describing the activities carried out and the objectives expected by both the teacher ( 4 out of a total of 8 activities) and the students (4 out of 8 ).

\section{FIGURE 2 \\ CONCEPTUALIZATION OF THE METHODOLOGY USED IN THE JIC AND SEQUENCING OF ACTIVITIES}

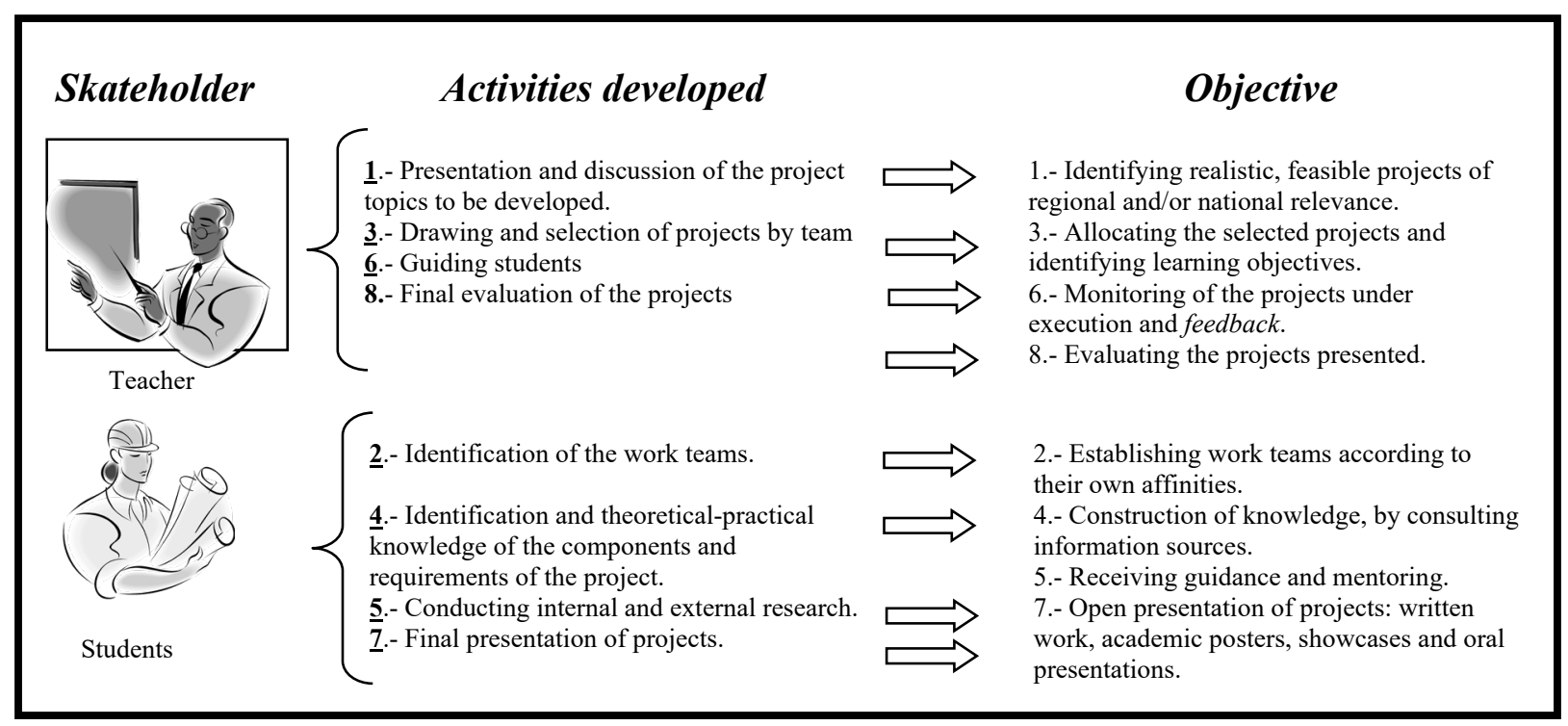

\section{Project Characteristics}

At the beginning of the class period, students are exposed to a series of projects, which have the following characteristics: real, practical, executable within the academic semester, technically and economically feasible and with future applications in the upcoming profession. Subsequently, and according to the number of work teams formed, the projects to be executed were selected at random, establishing the minimum learning objectives to be achieved, the necessary financial and bibliographic resources, the possibility of applying the autonomous learning methodology, and the distribution of the workload of the teacher and students.

It was taken into consideration that the projects proposed to the students should meet the characteristics that the ABPr's own projects should have, for example it must be relevant and of interest to the students, have clear objectives and stages, and present degrees of complexity, which translates into having different solutions and an interdisciplinary nature.

\section{Working Groups}

In the first course academic session, the teacher exposes the range of projects to be developed by a team consisting of 2 (minimum) to 4 (maximum) students for the collaborative development of projects and thus encourage teamwork. In this sense, the entire student body is asked to establish their work teams on a voluntary basis, in other words, looking for some kind of affinity among their peers (peer to peer 
interaction), to then proceed to the distribution of the selected projects. Depending on the number of work teams, as well as the number of different projects to be developed.

\section{RESULTS ACHIEVED}

As mentioned in previous paragraphs, in order to give continuity to this successful initiative, in 2015 the SIC is adopted as an institutional event and is specified with the name of JIC, it is a program that belongs to UTP, with the participation, at that time involving a total of 72 projects which represented the mobilization of more than 300 students engaged in this mega-activity. In order to disseminate the JIC with greater impact and project it nationally, the concept was presented to the Secretaría Nacional de Ciencia, Tecnología e Innovación - SENACYT (National Secretariat for Science, Technology and Innovation) and in 2016 the technical cooperation agreement No. 11-2016 was signed with the Technological University of Panama. One of the objectives of this agreement is to project the JIC at a national level, involving all public and/or private universities of the Republic of Panama accredited by CONEAUPA. This cooperation agreement was initially intended to last for four years (until 2019), but with the possibility of extension. The budget considered in the agreement is thirty thousand Balboas (B/. 30,000.00) per year. The logistics of the JIC are basically divided into five stages or phases: Induction or sensitization, dissemination, institutional selection or pre-selection, selection and awarding.

Among the participating universities in 2016-2017 were: ISAE University, Autonomous University of Chiriqui, University of Panama, University of Art Ganexa, University of the Isthmus, Specialized University of the Americas, Latin University of Panama, Inter-American University of Panama, Santa Maria la Antigua University and the Technological University of Panama. Regarding the Technological University of Panama, the number of participating projects has had a significant progress of 33 more projects in 2017, when compared to 2016. In the final selection of the pre-selected projects from the different university institutions throughout the country in 2016 and 2017, both students and their respective faculty advisors had the chance to attend all the conferences, workshops and exhibitions during the days of the corresponding national congresses described above.

For two successive years, the selected projects participate, representing the Republic of Panama, in international events of recognized trajectory and prestige for the promotion of research at the undergraduate level. In 2016 the team selected was from the University of Panama and for 2017 it was from the Azuero Regional University Center of the University of Panama. Both teams, in the respective years, had the opportunity to interact with their counterparts during the NCUR (National Conference on Undergraduate Research) in 2016 held at the University of Memphis and in 2017 at the University of Oklahoma, in the United States. In addition to the participation in the NCUR, both students and their advisor visit universities and research centers. 
FIGURE 3

\section{PICTURES OF THE PARTICIPATION OF THE JIC PANAMA 2016 WINNERS AT THE NATIONAL CONFERENCE ON UNDERGRADUATE RESEARCH 2017 - UNIVERSITY OF MEMPHIS}
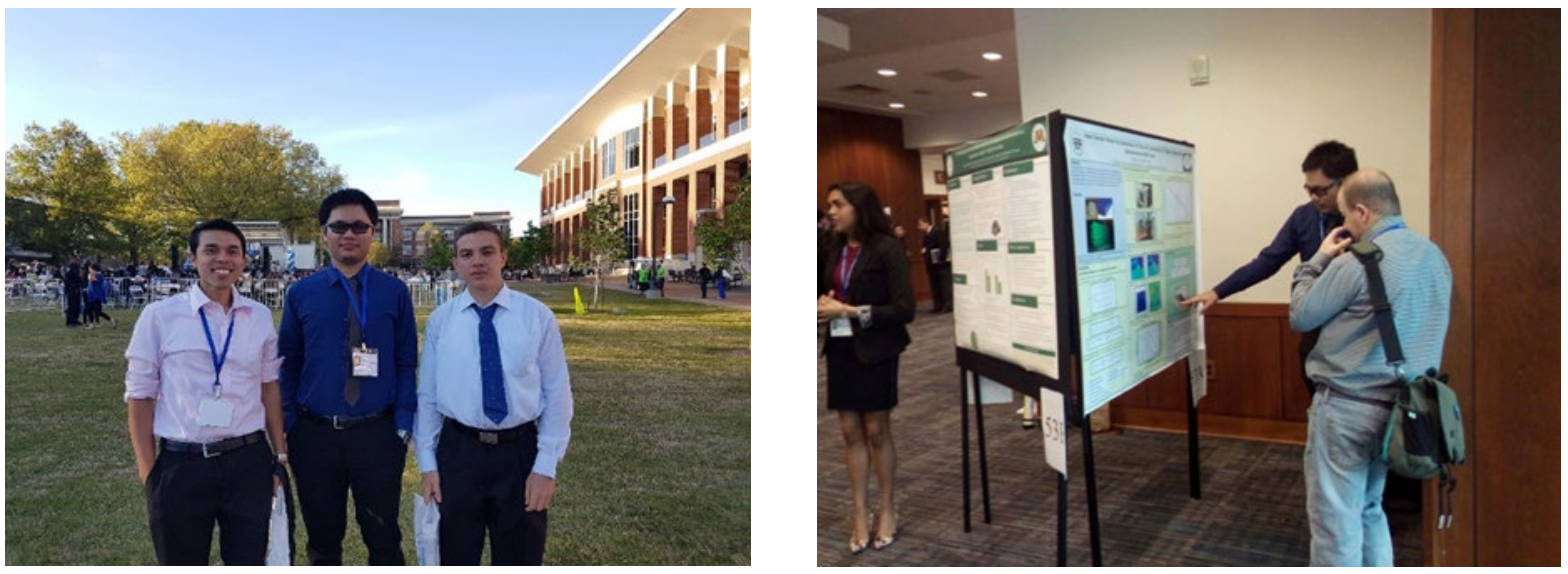

\section{CRITICAL ANALYSIS AND INTERPRETATION}

In these two years we have acquired valuable experiences that serve as baselines for the improvement and extension of this activity, thus identifying the following projections:

- Short term. To establish mechanisms to determine the number of projects pre-selected by each university institution. A category should be developed to identify projects based on minimum scores that must be obtained in order to move on to the next round and not based on the number of projects enrolled, as has been the case in the past.

- Medium term. Growth of the JIC, from two perspectives: The horizontality of the JIC in the Secondary Education of the Republic of Panama, through the participation of the Ministry of Education as a guest. In addition to national growth, in the medium term, a gradual extension to the Central American region is also contemplated through the intermediation of Consejo Superior de Universidades de Centro América - CSUCA (Central American Superior Council of Universities) by means of the JIC- CSUCA.

- Long term. To be part of the Council on Undergraduate Research (CUR) of the United States and Canada for the strengthening of the JIC at the international level.

\section{ACKNOWLEDGEMENT}

Translated \& edited by American Publishing Services (https://americanpublishingservices.com/).

\section{REFERENCES}

Ayas, C. (2006). An examination of the relationship between the integration of technology into social studies and constructivist pedagogies. The Turkish Online Journal of Education Technology, 5(12), 14-25.

Boud, D., \& Falchikov, N. (2006) Aligning assessment with long-term learning. Assessment \& Evaluation in Higher Education, 31(4), 399-413.

Dochy, F., Segers, M., Van den Bossche, P., \& Gijbels, D. (2006). Effects of problem-based learning: A meta-analysis. Learning and Instruction, 13, 533-568. 
Gallego Badillo, R. (2004). Un concepto epistemológico de modelo de la didáctica de las ciencias experimentales. Revista Electrónica de Enseñanza de las Ciencias Experimentales, 3(3), 301319.

Hmelo-Silver, C. (2004). Problem-based learning: What and how do students learn? Educational Psychology Review, 16(3), 235-266.

Hytte, K. (2007). Learning to think. Philosophy of Education, pp. 221-223.

Kolmos, A. (2004). Estrategias para desarrollar currículos basados en la formulación de problemas y organizados en base a proyectos. Educar, 33, 77-96.

Tejedor De León, A. (2016). IsCLA Modelo E\&A: Investigación en el salón de clases, modelo de enseñanza y aprendizaje. In P. Gudiño \& M. Escala (Comp.), Innovación interamericana en educación superior. Santo Domingo: Imp. Búho.

Tejedor De León, A. (2017). Aprendizaje basado en proyectos, experiencia didáctica en la asignatura Geología y utilización del Sílabo CDIO para su validación. In O. Jerez \& C. Silva (Eds.), Innovando en educación superior: experiencias clave en Latinoamérica y el Caribe 2016-2017. Volumen 2: Metodologías activas de enseñanza aprendizaje. Santiago, Chile, Facultad de Economía y Negocios, Universidad de Chile. 